\title{
Urinary $\beta 2$-Microglobulin Is a Good Indicator of Proximal Tubule Injury: A Correlative Study with Renal Biopsies
}

\author{
Xu Zeng, ${ }^{1}$ Deloar Hossain, ${ }^{2}$ David G. Bostwick, ${ }^{2}$ Guillermo A. Herrera, ${ }^{3}$ and Ping L. Zhang ${ }^{4}$ \\ ${ }^{1}$ Department of Pathology and Laboratory Medicine, Temple University Hospital, 3401 North Broad Street, \\ Room A2-F326, 2PAP, Philadelphia, PA 19140, USA \\ ${ }^{2}$ Bostwick Laboratories, Orlando, FL 32809, USA \\ ${ }^{3}$ Department of Pathology, Louisiana State University Health Sciences Center, Shreveport, LA 71103, USA \\ ${ }^{4}$ Department of Pathology, William Beaumont Hospital, Royal Oak, MI 48073, USA
}

Correspondence should be addressed to Xu Zeng; xu.zeng@tuhs.temple.edu

Received 26 August 2014; Revised 22 October 2014; Accepted 5 November 2014; Published 20 November 2014

Academic Editor: Rafael Noal Moresco

Copyright (C) 2014 Xu Zeng et al. This is an open access article distributed under the Creative Commons Attribution License, which permits unrestricted use, distribution, and reproduction in any medium, provided the original work is properly cited.

Objective. After filtration through glomeruli, $\beta 2$-microglobulin is reabsorbed in proximal tubules. Increased urinary $\beta 2$ microglobulin indicates proximal tubule injury and measurement of $\beta 2$-microglobulin in urine is useful to determine the source of renal injury. Kidney injury molecule-1 (KIM-1) has been characterized as a selective proximal tubule injury marker. This study was designed to evaluate the correlation of urinary $\beta 2$-microglobulin concentration and KIM-1 expression as evidence of proximal tubule injury. Methods. Between 2009 and 2012, 46 patients with urine $\beta 2$-microglobulin (RenalVysion) had followup kidney biopsy. Diagnoses included glomerular and tubule-interstitial disease. Immunohistochemical staining for KIM-1 was performed and the intensity was graded from 0 to $3+$. Linear regression analysis was applied to correlate the values of urinary $\beta 2$-microglobulin and KIM-1 staining scores. $P<0.05$ was considered statistically significant. Results. Thirty patients had elevated urinary $\beta 2$-microglobulin. KIM-1 staining was positive in 35 kidney biopsies. There was a significant correlation between urinary $\beta 2$-microglobulin and KIM-1 staining $(P<0.05)$. Sensitivity was $86.6 \%$, specificity was $43.7 \%$, positive predictive value was $74.2 \%$, and negative predictive value was $63.6 \%$. Conclusion. Increased urinary $\beta 2$-microglobulin is significantly correlated with KIM-1 staining in injured proximal tubules. Measurement of urine $\beta 2$-microglobulin is a sensitive assay for proximal tubule injury.

\section{Introduction}

Acute kidney injury is a common clinical syndrome that is characterized by a rapid decline in kidney function, often triggered by glomerular disease and/or tubulointerstitial disease and associated with high morbidity and mortality [1-4]. In addition to serum creatinine, $\beta 2$-microglobulin is a biomarker that can be used to determine underlying causes of acute kidney injury [5]. Serum $\beta 2$-microglobulin derives from cellular membrane turnover [6], since $\beta 2$ microglobulin forms the invariant light chain portion of major histocompatibility complex (MHC) class I in membranes of all cells [7-10]. As a single-chain small polypeptide $(\mathrm{MW}=11.8 \mathrm{kDA}), \beta 2$-microglobulin is filtered almost completely through the glomeruli of the healthy kidney $[11,12]$ and then reabsorbed by the renal proximal tubules. Only a small amount of $\beta 2$-microglobulin can be detected in the urine under normal physiological conditions. Therefore, levels of serum and urinary $\beta 2$-microglobulin reflect the functions of glomeruli and proximal tubules [13]. In patients with acute kidney injury, an increase in serum creatinine, together with an increase in urinary $\beta 2$-microglobulin, strongly suggests proximal tubule injury. On the other hand, an increase in serum creatinine with elevated serum $\beta 2$ microglobulin is seen in patients with decrease in glomerular filtration rate [14]. Elevated urinary $\beta 2$-microglobulin was associated with tubular injury caused by viral infection, ischemia, and toxicity from medications or heavy metals $[15,16]$.

Measurement of urinary $\beta 2$-microglobulin is convenient and has been applied in routine clinical practice (RenalVysion Bostwick Laboratories, Uniondale, NY) to evaluate 
the tubular function [17]. Using immunohistochemical staining for CD133 in kidney biopsies, we demonstrated that urinary $\beta 2$-microglobulin is a sensitive indicator for tubular injury [5]. However, a direct correlation between urinary $\beta 2$ microglobulin and proximal tubule injury has not yet been fully established due to lack of a specific proximal tubule injury marker.

Recently, kidney injury molecule-1 (KIM-1) was shown to be a biomarker for proximal tubule injury [18-20]. KIM-1 is a type 1 cell membrane glycoprotein comprised of extracellular, transmembrane and intracellular domains [21, 22]. KIM-1 is undetectable in the healthy kidney [19]. With different forms of kidney injury, mRNA and protein levels of KIM-1 are upregulated and expressed $[20,23,24]$ in injured tubules [23, 25-27]. KIM-1 binds to surface-specific epitopes on the apoptotic bodies and cellular debris derived from injured tubular cells, facilitating macrophages to engulf dying cells [19]. In addition, the extracellular domain of KIM-1 can be cleaved by metalloproteinases into a soluble shedded part and short membrane bound fragments that are released into urine. Therefore, the presence of KIM-1 in tubular epithelium and/or urine indicates tubule injury. Moreover, the expression of KIM-1 in injured tubule cells is limited to the proximal tubular cells [25]. Using immunohistochemistry, KIM-1 staining in kidney tissue has been shown to accurately detect proximal tubular injury associated with ischemic and toxic type of tubular injury, allograft rejection in renal transplantation, and acute pyelonephritis [20, 26, 28].

The present study was designed to examine the correlation between increase in urinary $\beta 2$-microglobulin and proximal tubule injury assessed by KIM-1 staining in kidney biopsies.

\section{Materials and Methods}

Between January 2009 and December 2012, a total of 5494 patients had urinary $\beta 2$-microglobulin measurements by RenalVysion analysis (Bostwick Laboratories). Among these, fifty-six patients had follow-up renal biopsies. Nine renal biopsies either contained less than 10 glomeruli per histological section or had insufficient tissue to perform immunohistochemical staining and were excluded from the present study. One biopsy showed high background staining and was also excluded. The remaining forty-six biopsies met selection criteria and were included in the present study.

Urine collection followed the instruction of RenalVysion. Briefly, $10 \mathrm{~mL}$ fresh urine was collected from each patient and urine $\mathrm{pH}$ was adjusted to $\mathrm{pH} 6-8$ with $1 \mathrm{M} \mathrm{NaOH}$. The specimen was delivered to lab by overnight shipping and the level of $\beta 2$-microglobulin was measured next day. The majority of immunohistochemical staining was performed in archived unstained slides prepared at the time of renal biopsy. In those biopsies in which unstained slides were not available, additional new slides were prepared from archival tissue from formalin-fixed paraffin-embedded blocks. All sections were cut at $3 \mu \mathrm{m}$. Each slide contained at least 2 sections.

Immunohistochemical staining for KIM-1 was conducted on paraffin slides using Dako autostainer (Dakocytomation, Carpinteria, CA). To remove paraffin, sections were heated at $60^{\circ} \mathrm{C}$ for $60 \mathrm{~min}$, placed into xylene baths for $3 \mathrm{~min}, 3$ times, followed by $100 \%$ alcohol, for $3 \mathrm{~min}, 3$ times, and then washed by running water for $30 \mathrm{~s}$. Antigen retrieval was carried out using a Tris-EDTA buffer at $\mathrm{pH} 8.0$ for $20 \mathrm{~min}$ at $99^{\circ} \mathrm{C}$ and cooled down for $20 \mathrm{~min}$ at room temperature, raised by tap water. Slides were placed into $\mathrm{H}_{2} \mathrm{O}_{2}$ for $15 \mathrm{~min}$ and then placed in Tris buffer ( $\mathrm{pH}$ 7.6). Finally, slides were placed into Dako autostainer programmed by Thermo Scientific UltraVision LP Detection System (Kalamazoo, MI). Staining procedures included 5 min Ultra V block, 30 min incubation with primary KIM-1 monoclonal antibody (AKG7 clone at 1:10 dilution, kindly provided by Dr. Joseph V. Bonventre from renal division Brigham and Women's Hospital, Boston), $8 \mathrm{~min}$ primary antibody enhancer, $10 \mathrm{~min}$ HRP polymer (equivalent to secondary antibody), and $5 \mathrm{~min}$ of chromogen DAB to achieve brown staining.

Granular staining in the cytoplasm and membrane of proximal tubular epithelium was considered positive. Staining intensity of KIM-1 was scored from 0 to $3+$ as follows: 0 , absence of staining; 0.5 , focal weak fine granular staining; $1+$, weak fine granular staining cytoplasm and/or membrane in entire tubular luminal surface; $2+$, moderate granular staining; and $3+$, strong coarse granular staining.

Patient charts were retrospectively reviewed. Demographic information, including age and gender, was recorded for each patient. Parameters related to tubular injury including serum creatinine, granular and cellular casts, and urine cytological findings were also recorded. Staining with KIM1 was evaluated by two pathologists who were blinded to the clinical data, final pathological diagnosis and patient outcome.

Linear regression analysis was used to correlate values of urinary $\beta 2$-microglobulin and KIM-1 staining scores. $P$ value $<0.05$ was considered statistically significant. Odds ratio analysis was applied to express the association of urinary $\beta 2$-microglobulin level and intensity of KIM-1 staining. Data were also stratified according to urinary $\beta 2$-microglobulin level as normal $(<300 \mu \mathrm{g} / \mathrm{L})$ versus increased to KIM-1 staining (positive or negative) and evaluated by $2 \times 2$ contingency table (Table 2). The sensitivity, specificity, predictive value for positive result, and predictive value for negative result were calculated as follows:

$$
\begin{aligned}
& \text { sensitivity = true positive/(true positive }+ \text { false nega- } \\
& \text { tive); } \\
& \text { specificity = true negative/(true negative }+ \text { false posi- } \\
& \text { tive); } \\
& \text { predictive value for positive result = true positive/(true } \\
& \text { positive + false positive); } \\
& \text { predictive value for negative result = true negative/(true } \\
& \text { negative }+ \text { false negative); }
\end{aligned}
$$

The age of the patients was expressed as mean \pm SD.

\section{Results}

Among 5494 patients with urinary $\beta 2$-microglobulin measurement, renal biopsy was obtained out in 56 patients 
(56/5494, 1.0\%). Among these, 46 biopsies met the selection criteria and were included in present study. Thirty patients had increases in urinary $\beta 2$-microglobulin; it was in normal range in the remaining 16 patients. The demographic details for 35 patients $(\mathrm{M}: \mathrm{F}=22: 13)$ with positive KIM-1 staining in proximal tubules are shown in Table 1 . The age of patients at the time of biopsy was $54.9 \pm 10.7$ years ranging from 16.0 to 87.0 years. The majority of renal biopsies were performed in native kidneys. Two biopsies were from renal transplant patients. A majority of renal biopsies showed glomerular disease. Nine patients had combined glomerular and tubulointerstitial involvement. Glomerular diseases included membranous nephropathy, antineutrophil cytoplasmic antibody- (ANCA-) associated glomerulonephritis, diabetic nephropathy, focal and segmental glomerulosclerosis, IgA nephropathy, and lupus nephritis. Four patients had acute interstitial nephritis. In addition to glomerular disease, five patients had tubular injury (Figures 1(c) and 1(d)), two of which were toxic type of injury with cytoplasmic vacuoles (Figure 1(d)). The remaining three biopsies showed ischemic tubular injury.

Of the 26 patients with elevated urinary $\beta 2$-microglobulin and positive KIM-1 staining in proximal tubules, 18 patients had increased serum creatinine, ranging from $1.50 \mathrm{mg} / \mathrm{dL}$ to $6.00 \mathrm{mg} / \mathrm{dL}$ (Table 1). Since the elevated urinary $\beta 2$-microglobulin is associated with proximal tubular injury [14], in these 18 patients it was considered that the proximal tubular injury is the primary cause of increase in serum creatinine. Nine patients with normal urinary $\beta 2$-microglobulin had positive KIM-1 staining in proximal tubules, 6 of which had increase in serum creatinine, ranging from $1.10 \mathrm{mg} / \mathrm{dL}$ to $3.20 \mathrm{mg} / \mathrm{dL}$. Granular casts were presented in 2 patients, who also had increase in both urinary $\beta 2$-microglobulin and serum creatinine. An increase in tubular epithelial cells was seen in 19/35 (54\%) patients. Eleven of 26 patients also had microscopic hematuria.

Thirty-five of 46 biopsies showed positive KIM-1 staining with a granular pattern in the cytoplasm and/or apical membrane of tubular epithelium, ranging from finely granular to coarsely granular (Figure 1(b)). Positive staining for KIM-1 was found in proximal tubules only. No staining in distal tubules, glomeruli, or vessels was seen. The corresponding H\&E slides of kidney biopsy showed flattening and simplification of tubular epithelium, ranging from focal to diffuse, overall focal tubular injury with varying degree, and mild tubular injury in the majority of the kidney biopsies. Staining intensity ranged from $0.5+$ to $3+$ with $1+$ staining in 18 patients $(18 / 35,51.4 \%)$. The relation between value of urinary $\beta 2$-microglobulin and KIM-1 staining score is shown in Figure 2. There was a significant correlation between levels of urinary $\beta 2$-microglobulin and KIM-1 staining $(R$ value $=$ $0.293, P<0.05$ ) (Figure 2). Odds ratio was 7.229, implying that levels of urinary $\beta 2$-microglobulin are strongly associated with intensity of KIM-1 staining. Confidence interval at the $95 \%$ range was 2.868 to 12.01 .

Among 35 biopsies with KIM-1 positive staining, 26 biopsies had increase in urinary $\beta 2$-microglobulin. The remaining 9 biopsies had normal urinary $\beta 2$-microglobulin (Table 2). Using positive KIM-1 staining as the end point, sensitivity was
$86.6 \%$, specificity was $43.7 \%$, positive predictive value was $74.2 \%$, and negative predictive value was $63.6 \%$.

\section{Discussion}

We found that increased urinary $\beta 2$-microglobulin was significantly correlated with KIM-1 staining in proximal tubules, indicating that urinary $\beta 2$-microglobulin is a sensitive (sensitivity $86.6 \%$ ) assay for detecting tubular injury. Further, because KIM-1 is a selective proximal tubule injury marker, the present study also demonstrated that measurement of urinary $\beta 2$-microglobulin was a reliable assay to detect proximal tubule injury. Therefore, in patients with acute kidney injury with increase in serum creatinine, measurement of urinary $\beta 2$-microglobulin is also helpful to identify the underlying tubular dysfunction, that is, proximal tubule injury.

Acute tubular injury is a common clinical diagnosis. In a patient with classic clinical presentations such as hypotension together with a rapid rising of serum creatinine, the diagnosis of severe tubular injury (acute tubular necrosis) can be made and does not require kidney biopsy to initiate treatment. However, the diagnosis of glomerular disease accompanied by tubular injury is not easy to establish, as both may contribute to elevated serum creatinine. As shown in Table 1 , the majority of kidney biopsies showed glomerular disease. Tubular injury was the secondary diagnosis in $5 / 35$ patients but other evidence of tubular injury such as tubular casts and an increase in tubular cells by urine analysis was found in 22/35 patients. Moreover, 2 of 4 patients with secondary diagnosis of acute interstitial nephritis showed tubulitis, a feature associated with tubular injury. These findings indicate that glomerular diseases associated with varying degree of tubular injury could be missed in renal biopsies due to sampling. In a prior study, using CD133 staining in injured tubular epithelium, it was demonstrated that urinary $\beta 2$ microglobulin was a sensitive indicator for tubular injury [5]. As a progenitor marker, CD133 positive cells were scattered along the tubular epithelium. Thus, confluent CD133 staining is required to diagnose tubular injury. In addition, CD133 positive cells are present not only in proximal tubular cells but also in distal tubular cells and/or atrophic tubules. Therefore, a careful morphological correlation is needed to exclude false positive staining. By comparison, KIM-1 is a selective proximal tubule injury marker that only presents in patients with proximal tubule injury [18-20]. No staining for KIM1 was seen in healthy tubular epithelium. No distal tubular cell or atrophic tubular cell staining was identified. Therefore, KIM-1 is a more specific marker than CD133 for detecting proximal tubular injury. In the present study, KIM-1 was able to detect patients with mild, focal tubular injury evidenced by urine analysis as an increase in number of tubular cells; some patients presented with normal levels of serum creatinine (Table 1). This was also supported with the finding in the present study that more than half of KIM-1 staining score was weakly positive (1+). These findings highlight that KIM1 is a sensitive marker for proximal tubular injury. A good correlation of urinary $\beta 2$-microglobulin and KIM- 1 staining 
TABLE 1: Clinical indices, diagnosis, concentration of $\beta 2$-microglobulin, serum creatinine, and urine analysis.

\begin{tabular}{|c|c|c|c|c|c|c|}
\hline Age (year) & Gender & Diagnosis & $\begin{array}{c}\beta 2- \\
\text { microglobulin } \\
(\mu \mathrm{g} / \mathrm{L})\end{array}$ & KIM score & $\begin{array}{l}\text { Serum } \\
\text { creatinine } \\
(\mathrm{mg} / \mathrm{dL})\end{array}$ & Urine analysis \\
\hline 53 & $\mathrm{~F}$ & IgA nephropathy & $<0.21$ & 0.5 & 0.9 & Hematuria \\
\hline 72 & M & Membranous nephropathy & $<0.21$ & 1.5 & 2.4 & $\begin{array}{l}\uparrow \text { Tubular cells, } \\
\text { hematuria }\end{array}$ \\
\hline 59 & $\mathrm{~F}$ & Diabetic nephropathy & $<0.21$ & 1.0 & 1.51 & $\uparrow$ Tubular cells \\
\hline 51 & $\mathrm{~F}$ & Focal, segmental glomerulosclerosis & $<0.21$ & 1.0 & 1.1 & Hematuria \\
\hline 46 & M & $\begin{array}{l}\text { Diabetic nephropathy, IgA } \\
\text { nephropathy }\end{array}$ & $<0.21$ & 2.0 & 2.5 & $\begin{array}{l}\uparrow \text { Tubular cells, } \\
\text { hematuria }\end{array}$ \\
\hline 37 & M & Lupus nephritis & $<0.21$ & 1.5 & 3.2 & $\begin{array}{l}\uparrow \text { Tubular cells, } \\
\text { hematuria }\end{array}$ \\
\hline 72 & $\mathrm{~F}$ & $\begin{array}{l}\text { Acute interstitial nephritis, IgA } \\
\text { nephropathy }\end{array}$ & $<0.21$ & 2.0 & 2.3 & Hematuria \\
\hline 69 & M & Membranous nephropathy & 0.28 & 1.0 & 0.99 & $\uparrow$ Tubular cells \\
\hline 87 & M & $\begin{array}{l}\text { IgA nephropathy, acute interstitial } \\
\text { nephritis }\end{array}$ & 0.29 & 2.0 & 3.2 & $\uparrow$ Tubular cells \\
\hline 50 & M & Lupus nephritis, tubular injury (toxic) & 0.31 & 3.0 & 0.64 & \\
\hline 83 & M & Diabetic nephropathy, tubular injury & 0.33 & 1.0 & 1.00 & \\
\hline 53 & $\mathrm{~F}$ & Focal, segmental glomerulosclerosis & 0.47 & 1.0 & 2.40 & $\uparrow$ Tubular cells \\
\hline 60 & M & IgA nephropathy, tubular injury & 0.49 & 2.0 & 5.00 & $\begin{array}{l}\uparrow \text { Tubular cells, } \\
\text { hematuria }\end{array}$ \\
\hline 29 & M & Renal transplantation, tubular injury & 0.53 & 2.0 & 4.50 & $\begin{array}{l}\uparrow \text { Tubular cells, } \\
\text { hematuria }\end{array}$ \\
\hline 35 & M & IgA nephropathy & 0.54 & 2.0 & 2.90 & $\begin{array}{l}\uparrow \text { Tubular cells, } \\
\text { hematuria }\end{array}$ \\
\hline 49 & M & Lupus nephritis & 0.63 & 3.0 & 1.03 & $\uparrow$ Tubular cells \\
\hline 68 & M & Focal, segmental glomerulosclerosis & 0.69 & 1.0 & 1.15 & Hematuria \\
\hline 44 & $\mathrm{~F}$ & Focal, segmental glomerulosclerosis & 1.15 & 1.0 & 1.10 & $\begin{array}{l}\uparrow \text { Tubular cells, } \\
\text { hematuria }\end{array}$ \\
\hline 16 & $\mathrm{~F}$ & Focal, segmental glomerulosclerosis & 1.60 & 3.0 & 2.00 & $\begin{array}{l}\uparrow \text { Tubular cells, } \\
\text { hematuria }\end{array}$ \\
\hline 52 & $\mathrm{~F}$ & Granuloma & 1.89 & 2.0 & 0.70 & $\uparrow$ Tubular cells \\
\hline 50 & M & IgA nephropathy & 1.89 & 2.0 & 0.83 & \\
\hline 20 & M & Normal & 4.52 & 1.0 & 3.26 & $\uparrow$ Tubular cells \\
\hline 47 & M & Focal, segmental glomerulosclerosis & 5.36 & 2.0 & 1.18 & $\begin{array}{l}\uparrow \text { Tubular cells, } \\
\text { hematuria }\end{array}$ \\
\hline 47 & M & Renal transplantation & 5.44 & 2.0 & 1.19 & Hematuria \\
\hline 74 & M & Focal, segmental glomerulosclerosis & 6.23 & 3.0 & 1.50 & Granular casts \\
\hline 63 & $\mathrm{~F}$ & Focal, segmental glomerulosclerosis & 7.19 & 1.0 & 4.50 & $\begin{array}{l}\uparrow \text { Tubular cells, } \\
\text { hematuria }\end{array}$ \\
\hline 38 & M & Diabetic nephropathy & 7.87 & 2.0 & 3.00 & Granular casts \\
\hline 77 & $\mathrm{~F}$ & ANCA-associated glomerulonephritis & 9.23 & 3.0 & 2.90 & \\
\hline 73 & M & ANCA-associated glomerulonephritis & 12.9 & 1.5 & 2.30 & \\
\hline 63 & M & $\begin{array}{l}\text { Diabetic nephropathy, tubular injury } \\
\text { (toxic) }\end{array}$ & 16.1 & 1.0 & 6.00 & $\uparrow$ Tubular cells \\
\hline 42 & M & Focal, segmental glomerulosclerosis & 29.8 & 1.0 & 1.70 & Neutrophils \\
\hline 62 & $\mathrm{~F}$ & Focal, segmental glomerulosclerosis & 35.9 & 3.0 & 7.10 & $\uparrow$ Tubular cells \\
\hline 68 & $\mathrm{~F}$ & Focal, segmental glomerulosclerosis & 46.3 & 2.0 & 2.50 & $\uparrow$ Tubular cells \\
\hline 53 & $\mathrm{~F}$ & Acute interstitial nephritis & 47.2 & 1.0 & 5.60 & $\uparrow$ Tubular cells \\
\hline 60 & M & Acute interstitial nephritis & 79.8 & 2.0 & 4.50 & $\uparrow$ Tubular cells \\
\hline
\end{tabular}




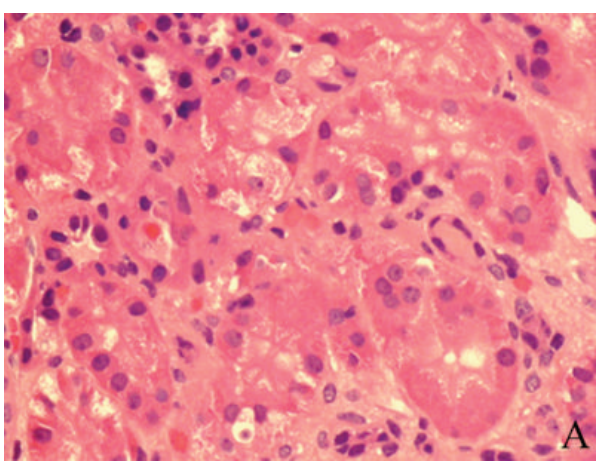

(a)

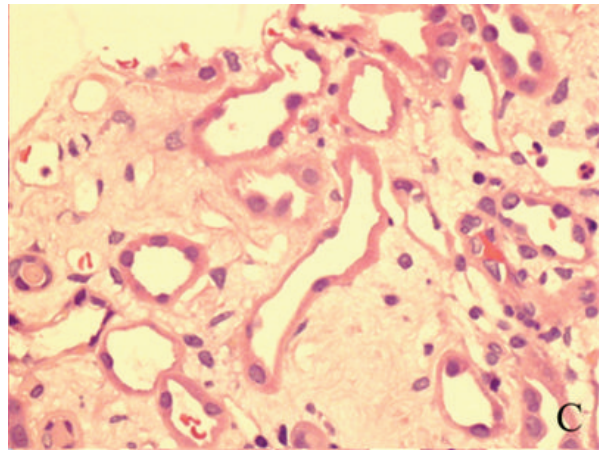

(c)

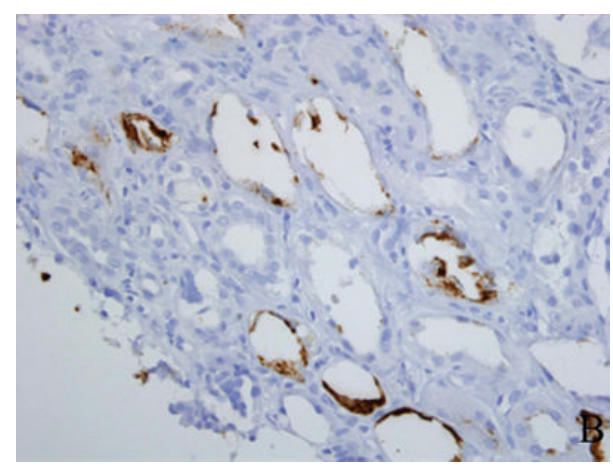

(b)

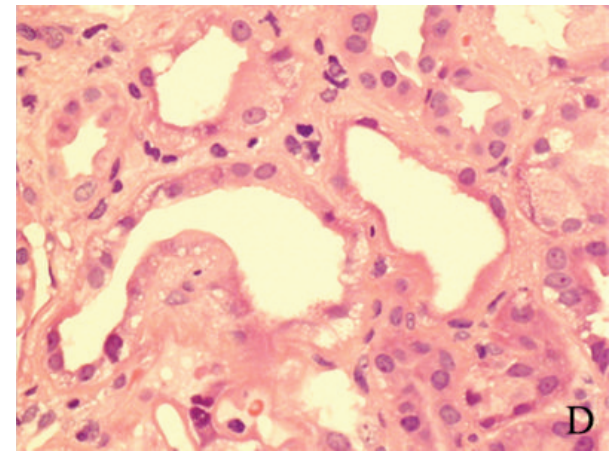

(d)

FIGURE 1: (a) Normal proximal tubules with back to back proximal tubules and abundant cytoplasm (H\&E $40 \times 10)$. (b) In addition to flattening and simplification of tubular epithelium, injured proximal tubules show granular cytoplasmic and membrane staining for KIM-1 (20 $\times 10)$. (c) Ischemia type of tubular injury shows flattening and simplification of tubular epithelium $(\mathrm{H} \& \mathrm{E} 40 \times 10)$. (d) In addition to flattened tubular epithelium, toxic type of tubular injury reveals vacuoles in cytoplasm $(\mathrm{H} \& \mathrm{E} 40 \times 10)$.

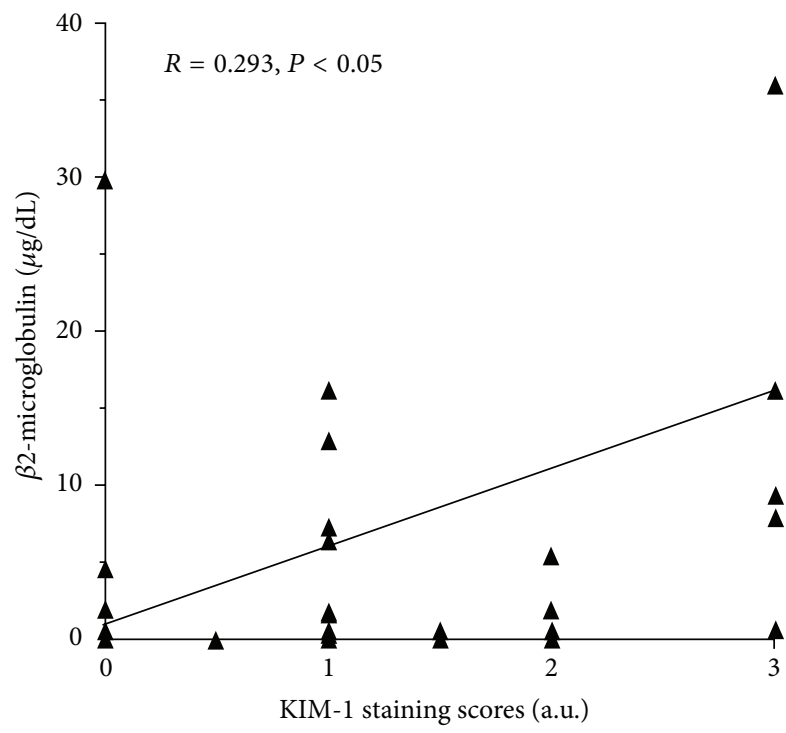

FIGURE 2: Linear regression analysis shows a significant correlation between levels of urinary $\beta 2$-microglobulin and KIM-1 staining scores $(R$ value $=0.293, P<0.05)$. Odds ratio was 7.229. Confidence interval at $95 \%$ range was 2.868 to 12.01 .

( $R$ value of 0.293$)$ indicates that measurement of urinary $\beta 2$ microglobulin is a reliable assay for proximal tubule injury.
Similar to CD133 staining, KIM-1 was also able to identify two major types of tubular injury: ischemic and toxic type (Figures 1(c) and 1(d)). As shown in Table 2, tubular injury was an additional diagnosis included in 5 of 26 biopsies (25\%) (Table 1), and all showed positive KIM-1 staining in proximal tubules.

Using KIM-1 staining as a proximal tubule injury marker in the present study, specificity was lower than the prior study that used CD133 staining [5]. Nine patients, rather than six patients with normal urinary $\beta 2$-microglobulin, presented with positive KIM-1 staining, which were considered false positive. With low specificity, clinical interpretation of elevated urinary $\beta 2$-microglobulin should be closely correlated with clinical history, (e.g., history of hypotension, recent history of medications use, etc.) and clinical presentation, including value of serum creatinine, as well as urine cytological findings. The diagnosis of tubular injury with RenalVysion was made not only based on the elevation of urinary $\beta 2$ microglobulin and serum creatinine but also combined with morphological findings of tubular casts and the number of sloughed tubular epithelial cells in urine analysis.

RenalVysion is a urine-based analysis that combines urine chemistry and cytology to detect glomerular disease and tubular injury. Normal range of urinary $\beta 2$-microglobulin was set between $230 \mu \mathrm{g} / \mathrm{L}$ and $300 \mu \mathrm{g} / \mathrm{L}$ [29]. Elevation of urinary $\beta 2$-microglobulin over $300 \mu \mathrm{g} / \mathrm{L}$ was considered to be abnormal by RenalVysion. Therefore, nine patients with 
TABLE 2: Correlation of urinary $\beta 2$-microglobulin and KIM-1 staining.

\begin{tabular}{lcc}
\hline & KIM-1 (+) & KIM-1 (-) \\
\hline $\begin{array}{l}\beta 2 \text {-microglobulin } \\
\text { increase (30) }\end{array}$ & 26 & 4 \\
$\begin{array}{l}\beta 2 \text {-microglobulin } \\
\text { normal (16) }\end{array}$ & 9 & 7 \\
\hline
\end{tabular}

urinary $\beta 2$-microglobulin $<300 \mu \mathrm{g} / \mathrm{L}$ and positive KIM-1 staining in biopsies were considered to be false positive. However, the actual values of urinary $\beta 2$-microglobulin in 2 patients were marginally high in $280 \mu \mathrm{g} / \mathrm{L}$ and $290 \mu \mathrm{g} / \mathrm{L}$. The remaining 7 patients were found to have levels less than $210 \mu \mathrm{g} / \mathrm{L}$, which is the measurement threshold of the assay. Because the confidence interval at the $95 \%$ range in lower end was 2.868 in present study, the normal range of urinary $\beta 2$-microglobulin applied in RenalVysion should be reconsidered to be $2.868 \mu \mathrm{g} / \mathrm{L}$. If so, the patient with urinary $\beta 2$-microglobulin of $290 \mu \mathrm{g} / \mathrm{L}$ should be considered as abnormal and belongs to true positive for KIM-1 staining. Therefore, corrected sensitivity is $87.1 \%$, specificity is $46.6 \%$, positive predictive value is $77.1 \%$, and negative predictive value is $63.6 \%$.

Our study has multiple limitations. Only a small number of patients had follow-up renal biopsies after RenalVysion (56/5494, 1.0\%), raising concern for selection and ascertainment biases. As shown in Table 1, these patients had glomerular disease and/or tubular-interstitial disease. No severe tubular injury as the single diagnosis was seen. The reason for this might be that renal biopsy is usually avoided in patients with a clear clinical diagnosis of severe tubular injury. A larger study cohort involving patients with severe tubular injury is needed to better correlate renal histopathology and immunohistochemistry. Owing to limited sampling by biopsies, a focal tubular lesion might be missed in kidney biopsies chosen in present study. The retrospective nature of the study represents an additional limitation.

In summary, measurement of urinary $\beta 2$-microglobulin is a sensitive assay to screen patients with proximal tubule injury. Our data indicate a correlation of urinary $\beta 2$ microglobulin with results of immunohistochemical staining of KIM-1 in renal biopsy and consequently with proximal tubular injury.

\section{Conflict of Interests}

The authors declare that there is no conflict of interests regarding the publication of this paper.

\section{Acknowledgments}

The authors would like to acknowledge the technical support from Betty Ballester and Etnita NuNez in their professional preparation of histological slides. This work was presented at the annual meeting of the American Society of Nephrology, Philadelphia, PA, USA, November 2014.

\section{References}

[1] G. M. Chertow, E. Burdick, M. Honour, J. V. Bonventre, and D. W. Bates, "Acute kidney injury, mortality, length of stay, and costs in hospitalized patients," Journal of the American Society of Nephrology, vol. 16, no. 11, pp. 3365-3370, 2005.

[2] J. L. Xue, F. Daniels, R. A. Star et al., "Incidence and mortality of acute renal failure in medicare beneficiaries, 1992 to 2001," Journal of the American Society of Nephrology, vol. 17, no. 4, pp. 1135-1142, 2006.

[3] M. T. James, R. Wald, C. M. Bell et al., "Weekend hospital admission, acute kidney injury, and mortality," Journal of the American Society of Nephrology, vol. 21, no. 5, pp. 845-851, 2010.

[4] J.-P. Lafrance and D. R. Miller, "Acute kidney injury associates with increased long-term mortality," Journal of the American Society of Nephrology, vol. 21, no. 2, pp. 345-352, 2010.

[5] X. Zeng, D. Hossain, D. Bostwick, G. Herrera, B. Ballester, and P. L. Zhang, "Urinary $\beta 2$-microglobulin is a sensitivie indicator for renal tubular injury," Scholarena Case Reports, vol. 1, no. 1, pp. 103-108, 2014.

[6] M. D. Poulik and R. A. Reisfeld, "Beta2-microglobulins," Contemporary Topics in Molecular Immunology, vol. 4, pp. 157-204, 1975.

[7] P. J. Bjorkman, M. A. Saper, B. Samraoui, W. S. Bennett, J. L. Strominger, and D. C. Wiley, "Structure of the human class I histocompatibility antigen, HLA-A2," Nature, vol. 329, no. 6139, pp. 506-512, 1987.

[8] M. A. Saper, P. J. Bjorkman, and D. C. Wiley, "Refined structure of the human histocompatibility antigen HLA-A2 at 2-6 $\AA$ resolution," Journal of Molecular Biology, vol. 219, no. 2, pp. 277319, 1991.

[9] E. J. Collins, D. N. Garboczi, M. N. Karpusas, and D. C. Wiley, "The three-dimensional structure of a class I major histocompatibility complex molecule missing the alpha 3 domain of the heavy chain," Proceedings of the National Academy of Sciences of the United States of America, vol. 92, no. 4, pp. 1218-1221, 1995.

[10] J. B. Lindblom, L. Oestberg, and P. A. Peterson, “ $\beta 2-$ Microglobulin on the cell surface. Relationship to HL A antigens and the mixed leucocyte culture reaction," Tissue Antigens, vol. 4, no. 2, pp. 186-196, 1974.

[11] U. Ravnskov, "Letter: serum beta2-microglobulin and glomerular function," The New England Journal of Medicine, vol. 294, no. 11, p. 611, 1976.

[12] C. Bianchi, C. Donadio, G. Tramonti, C. Consani, P. Lorusso, and G. Rossi, "Reappraisal of serum $\beta 2$-microglobulin as marker of GFR," Renal Failure, vol. 23, no. 3-4, pp. 419-429, 2001.

[13] B. Bussolati and G. Camussi, "New insights into the renal progenitor cells and kidney diseases by studying CD133," Advances in Experimental Medicine and Biology, vol. 777, pp. 113-123, 2013.

[14] C. Donadio, "Serum and urinary markers of early impairment of GFR in chronic kidney disease patients: diagnostic accuracy of urinary $\beta$-trace protein," The American Journal of Physiology-Renal Physiology, vol. 299, no. 6, pp. F1407-F1423, 2010.

[15] B. Bogdanikowa, " $\beta 2$ microglobulin-its properties, occurrence and diagnostic usefulness," Postepy Higieny Medycyny Doswiadczalnej, vol. 35, no. 5, pp. 495-510, 1981.

[16] N. Häring, H. S. Mähr, M. Mündle, R. Strohal, and K. Lhotta, "Early detection of renal damage caused by fumaric acid ester therapy by determination of urinary $\beta 2$-microglobulin," British Journal of Dermatology, vol. 164, no. 3, pp. 648-651, 2011. 
[17] R. J. Trof, F. di Maggio, J. Leemreis, and A. B. J. Groeneveld, "Biomarkers of acute renal injury and renal failure," Shock, vol. 26, no. 3, pp. 245-253, 2006.

[18] J. V. Bonventre and L. Yang, "Kidney injury molecule-1," Current Opinion in Critical Care, vol. 16, no. 6, pp. 556-561, 2010.

[19] F. Waanders, M. M. van Timmeren, C. A. Stegeman, S. J. L. Bakker, and H. van Goor, "Kidney injury molecule-1 in renal disease," The Journal of Pathology, vol. 220, no. 1, pp. 7-16, 2010.

[20] W. K. Han, V. Bailly, R. Abichandani, R. Thadhani, and J. V. Bonventre, "Kidney injury molecule-1 (KIM-1): a novel biomarker for human renal proximal tubule injury," Kidney International, vol. 62, no. 1, pp. 237-244, 2002.

[21] Z. Zhang, B. D. Humphreys, and J. V. Bonventre, "Shedding of the urinary biomarker kidney injury molecule-1 (KIM-1) is regulated by MAP kinases and juxtamembrane region," Journal of the American Society of Nephrology, vol. 18, no. 10, pp. 27042714, 2007.

[22] V. Bailly, Z. Zhang, W. Meier, R. Cate, M. Sanicola, and J. V. Bonventre, "Shedding of kidney injury molecule-1, a putative adhesion protein involved in renal regeneration," The Journal of Biological Chemistry, vol. 277, no. 42, pp. 39739-39748, 2002.

[23] T. Ichimura, J. V. Bonventre, V. Bailly et al., "Kidney injury molecule-1 (KIM-1), a putative epithelial cell adhesion molecule containing a novel immunoglobulin domain, is up-regulated in renal cells after injury," The Journal of Biological Chemistry, vol. 273, no. 7, pp. 4135-4142, 1998.

[24] V. S. Vaidya, S. S. Waikar, M. A. Ferguson et al., "Urinary biomarkers for sensitive and specific detection of acute kidney injury in humans," Clinical and Translational Science, vol. 1, no. 3, pp. 200-208, 2008.

[25] M. M. van Timmeren, M. C. van den Heuvel, V. Bailly, S. J. L. Bakker, H. van Goor, and C. A. Stegeman, "Tubular kidney injury molecule-1 (KIM-1) in human renal disease," The Journal of Pathology, vol. 212, no. 2, pp. 209-217, 2007.

[26] T. Ichimura, C. C. Hung, S. A. Yang, J. L. Stevens, and J. V. Bonventre, "Kidney injury molecule-1: a tissue and urinary biomarker for nephrotoxicant-induced renal injury," American Journal of Physiology-Renal Physiology, vol. 286, no. 3, pp. F552-F563, 2004.

[27] A. B. Kramer, M. M. van Timmeren, T. A. Schuurs et al., "Reduction of proteinuria in adriamycin-induced nephropathy is associated with reduction of renal kidney injury molecule (Kim-1) over time," The American Journal of Physiology-Renal Physiology, vol. 296, no. 5, pp. F1136-F1145, 2009.

[28] W. S. Oetting, T. B. Rogers, T. P. Krick, A. J. Matas, and H. N. Ibrahim, "Urinary $\beta_{2}$-microglobulin is associated with acute renal allograft rejection," American Journal of Kidney Diseases, vol. 47, no. 5, pp. 898-904, 2006.

[29] V. S. Klimenko, V. N. Titov, V. P. Masenko, and P. M. Leshchinskiü, "Beta 2-microglobulin concentration in the blood and urine," Laboratornoe Delo, no. 2, pp. 107-110, 1982. 


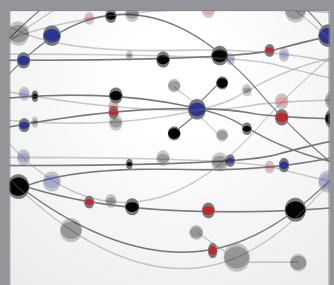

The Scientific World Journal
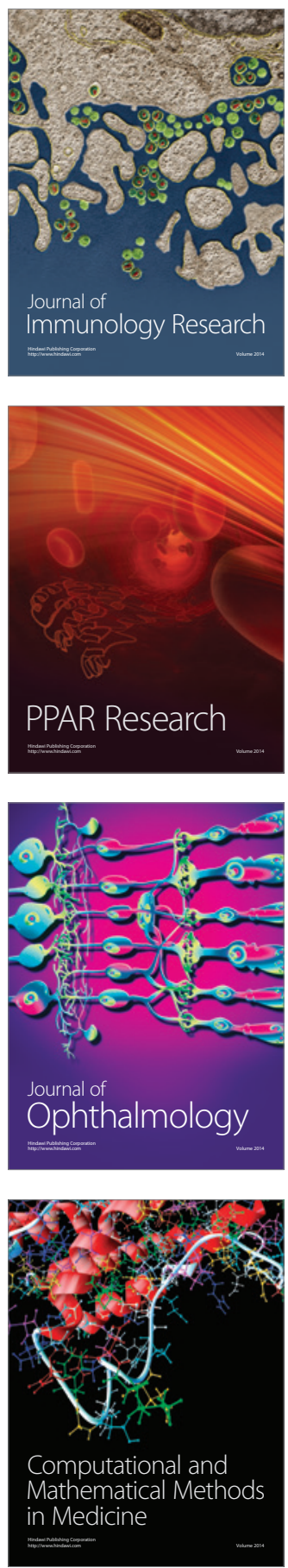

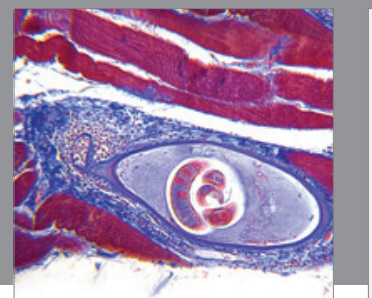

Gastroenterology

Research and Practice
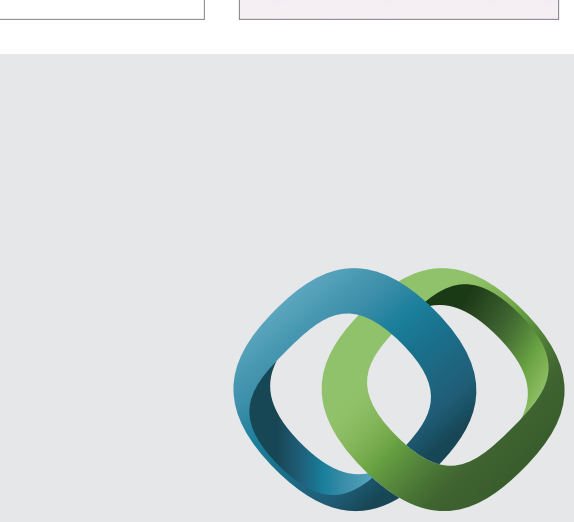

\section{Hindawi}

Submit your manuscripts at

http://www.hindawi.com
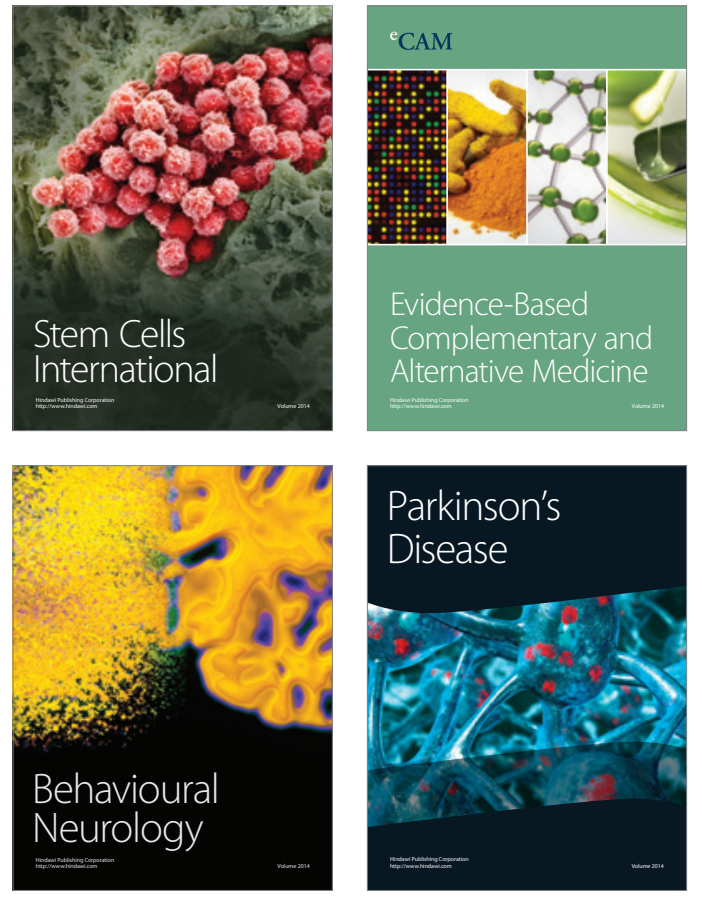
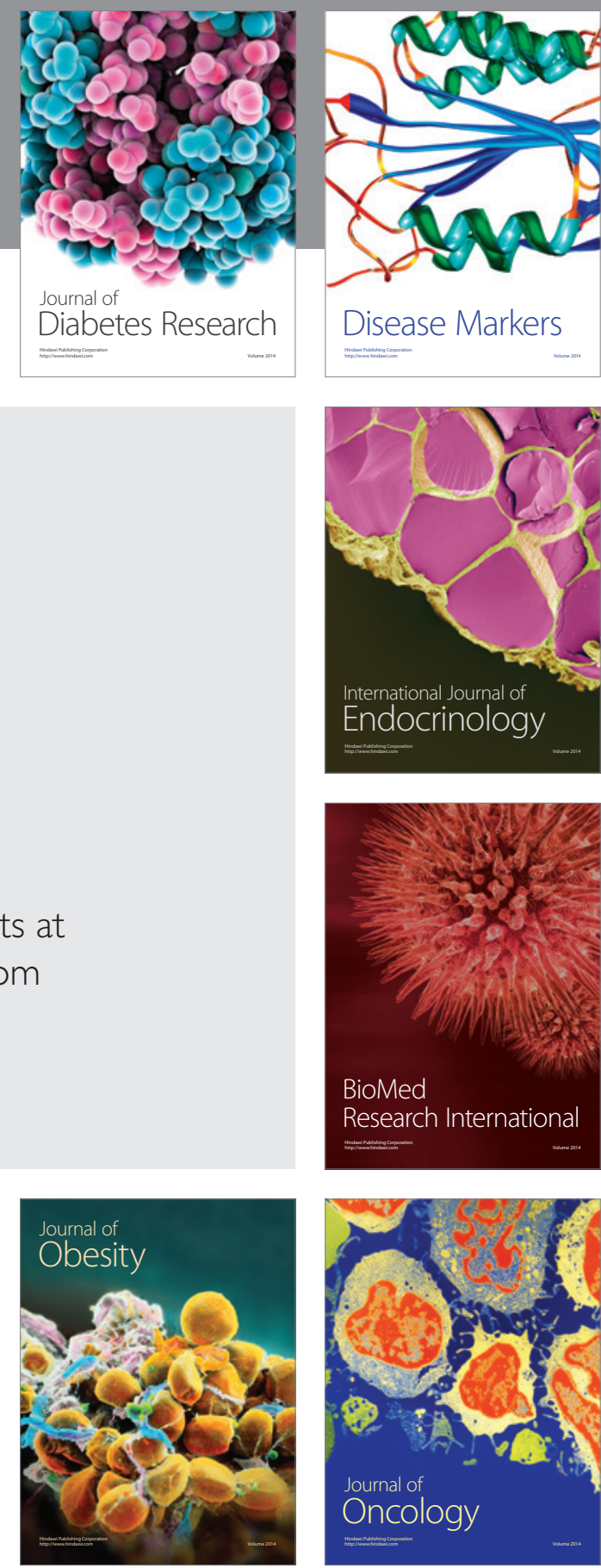

Disease Markers
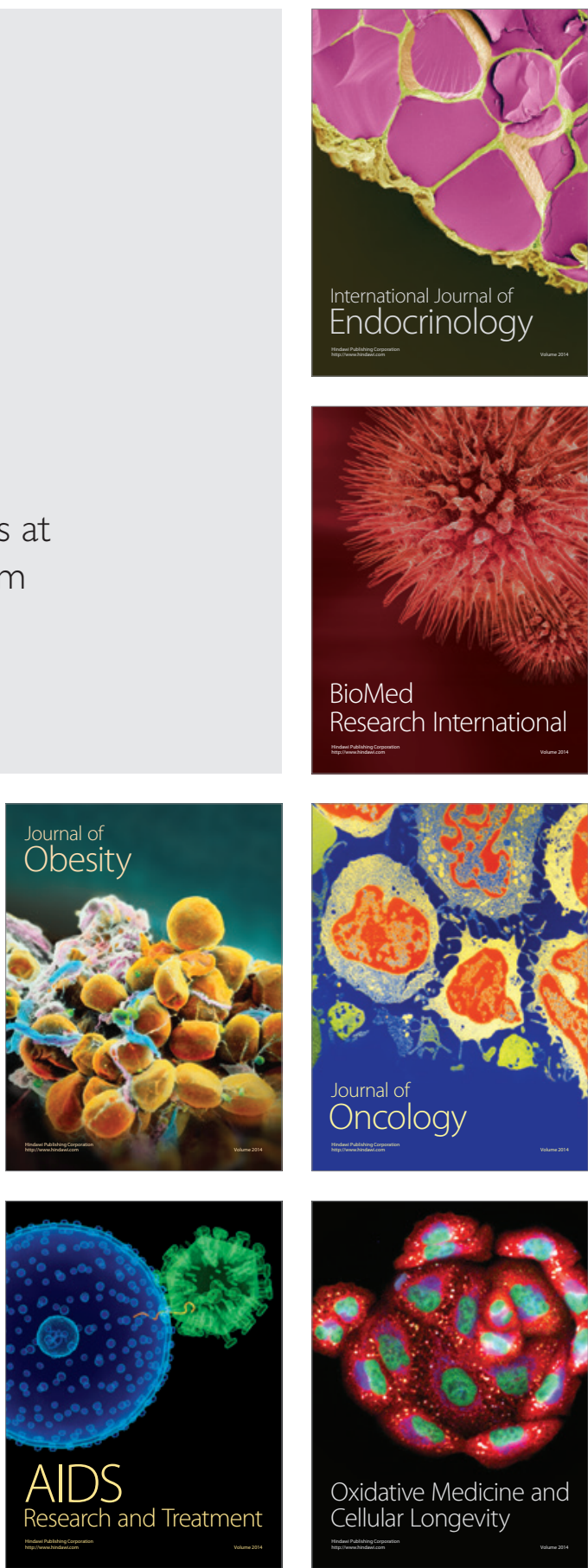